\title{
A habitat for sustainability experiments: Success factors for innovations in their local and regional contexts
}

\author{
Harm A.R.M. van den Heiligenberg ${ }^{\text {a, }}$, Gaston J. Heimeriks ${ }^{a}$, Marko P. Hekkert ${ }^{\text {a }}$, \\ Frank G. van Oort ${ }^{b}$
}

${ }^{a}$ Copernicus Institute of Sustainable Development, Utrecht University, Heidelberglaan 2, 3584 CS, Utrecht, The Netherlands

${ }^{\mathrm{b}}$ Erasmus School of Economics, Erasmus University, Burgemeester Oudlaan 50, 3000 DR, Rotterdam, The Netherlands

\section{A R T I C L E I N F O}

\section{Article history:}

Received 29 April 2016

Received in revised form

16 May 2017

Accepted 19 June 2017

Available online 22 June 2017

Handling Editor: Cecilia Maria Villas Bôas de

\section{Keywords:}

Sustainability

Regional innovation

Experimentation

Transitions

Upscaling

\begin{abstract}
A B S T R A C T
The sustainability challenge requires various forms of experimentation with inventions, which may lead to an upscaling process in which the invention and its applications will spread to other users and regions in the world. However, many experiments fail. In this paper, we explore the success factors for sustainability experiments in their contribution to a longer-term regime change. These factors are related to the experiment itself as well as to the habitat in which the experiment takes place. A habitat is regarded as a configuration of contextual factors, which are mainly locally or regionally embedded. We introduce complementary insights from transition management literature and regional innovation systems literature to hypothesise that various types of experiments have distinctive favourite habitats, each with their specific success factors. Our exploratory survey among 56 sustainability experiments throughout Europe in the area of food, mobility and energy innovation suggests that user involvement is the most important success factor. Other important factors are the cooperation in local and regional networks, the policy instruments from the local and regional government, the dissemination of learning experiences, and the existence of a local or regional vision of the future. We conclude that entrepreneurs, users, local and regional governments as well as other regional partners should collaborate actively to make sustainability experiments more successful.
\end{abstract}

๑) 2017 Elsevier Ltd. All rights reserved.

\section{Introduction}

Sustainable development is one of the crucial societal challenges of our times. On a global scale, issues such as food security, poverty, climate change, water availability, and biodiversity demand urgent attention. On national and regional scales, food, mobility and energy systems can be greatly improved. To accommodate these challenges, however, transitions are needed, i.e. large-scale societal changes that take several decades to complete. An important element in the transition process is the experimentation phase. In this phase, inventions are tested in specific local and regional contexts. In society and policy, there are high expectations that successful experiments will stimulate both upscaling mechanisms and the economic viability of the innovations needed in the transition process. In this upscaling process, the invention is

\footnotetext{
* Corresponding author.

E-mail address: harm.van.den.heiligenberg@provincie-utrecht.nl (H.A.R.M. van den Heiligenberg).
}

improved and diffused to other locations and regions in the world, which may lead to the necessary transition. However, in reality these upscaling mechanisms often do not materialise. Worldwide, thousands of sustainability experiments have been carried out, but many have actually failed, i.e. they do not scale up (OECD \& World Bank, 2014). There is a clear societal need to gain insight into the success factors of sustainability experiments in their contribution to upscaling towards a longer-term regime change.

Crucial for understanding both the success of experiments and upscaling opportunities are the conceptualisations of success and of conditioning spatial embedding circumstances. This paper wants to contribute to both these issues, using conceptually informed empirical research.

Complementary to the present transition literature, we introduce a broad definition of experiment success, distinguishing two dimensions: 
a. success in the short term, i.e. whether the experiment achieves its short-term targets;

b. success in the long term, i.e. whether the experiment contributes to upscaling to a longer-term regime change.

We introduce such a broad definition because both dimensions of success are probably linked: short-term success may trigger long-term success. Alternatively, we may learn from an experiment that fails to achieve its short-term targets but still contributes to a longer-term regime change.

In this paper we develop the notion that the experimentation phase in sustainability transitions is a crucial phase. In this phase (between prototype and upscaling), a prototype is made available, but it is not yet clear whether the innovation will scale up. We define upscaling of transition experiments as (i) an increase in the number of users and (ii) the embedding of experiments in the existing structures of the regime, i.e. perspectives, ways of thinking, routines, legislation and institutions (Rotmans and Loorbach, 2010). The increase in the number of users may occur either in the region in which the experiment has been embedded or elsewhere, given the cognitive understanding of innovation (Ponds et al., 2010).

Some transition management research focuses on the identification of the success factors for sustainability experiments. However, in this research tradition the geographical dimension is initially lacking. The geography is relevant because transition processes are unevenly distributed in space: they initiate in and diffuse to some places more than to other places (Hansen and Coenen, 2014; Boschma, 2005). By focusing on the success factors of an experiment as well as on the geographical context of the experiment (the habitat), we shed light on the hypothesis that local and regional environments potentially contribute to experiment success. Originally stemming from biology, we introduce the habitat concept in transition research to suggest that experimentation is carried out in co-evolution with its geographical context. In transition research, the process of co-evolution is well known (e.g. Schot and Geels, 2008), although not in a geographically explicit form. Furthermore, we suggest that various functional types of habitats may overlap in a geographical sense.

Our research question is the following: what are the major success factors, barriers and upscaling mechanisms of European sustainability experiments in their geographical context? A focus on the European dimension warrants the capturing of heterogeneity in local and regional contexts, such as institutional variations in structural change processes (Cortinovis et al., 2017) and variations in place-based and regional policies (Barca et al., 2012). We zoom in on the local and regional contexts across European countries, but we are interested in factors on all scales from local to global. Regions are a particular unit at which innovative experimentation occurs, because of for instance the (skilled) labour market and institutional and policy conditions. In this paper we focus on sustainability experiments in living labs, which offer promising preconditions for success. In relation to this, we focus on success factors contributing to upscaling towards a longer-term regime change. With respect to the upscaling mechanism, we focus on two aspects: the links with previous and the following experiments and the dedicated activities carried out in the experiment to promote future upscaling.

Scientifically, we aim at making an empirical contribution to the emerging field of the geography of transitions. We address the research gap on how the geographical context and scale matter in sustainability experimentation. From a societal perspective, this research is aimed at bringing relevant insights to the stakeholders involved in sustainability experimentation. These insights may be used to enhance the success of sustainability experiments in future.

\section{Background}

Several bodies of literature address topics relevant to answering our research question. We argue that it is necessary to combine insights from two different research fields: the transition management literature (TM), which addresses sustainability experiments, especially concerning strategic niche management (SNM), and the regional innovation system literature (RIS), which explicitly focuses on the geographical context of innovation. The combination of these two bodies of literature generates complementary insights.

\subsection{Transition management}

In the TM and SNM literature, two concepts are relevant to our research: the multi-level perspective and the multi-phase model. In the multi-level perspective, a novelty is created on the niche level (a novelty is called an invention in innovation literature). A transition process occurs if the novelty, which emerges on the niche level, enters the regime, spurred by changing landscape level conditions (Geels, 2002). We consider a niche a space where experimentation is carried out. However, the geographical dimensions of this space are not defined in transition literature.

The multi-phase model is different from the multi-level perspective, and describes the various phases in transitions. Experimentation and learning predominantly occur in the take-off phase. We are interested in the factors that facilitate the upscaling of experiments. These upscaling processes occur in the next phase, i.e. the breakthrough phase (Rotmans et al., 2001).

In the SNM literature, an experiment has a specific set of meanings related to the seeds of change that may lead to a transformation in the way in which human needs are met (Sengers et al., 2016). A sustainability experiment is sometimes also defined as a purposive and strategic intervention that explicitly seeks to capture new forms of learning or experience (Castán Broto and Bulkeley, 2013). In other words, sustainability experiments are focused on a future goal.

Experimentation and possibly subsequent upscaling are not simple linear processes. There is a high level of risk involved in terms of failure (Rotmans, 2005). Upscaling requires series of transition experiments in various niches (Raven et al., 2010). In these niches, various processes of nurturing and empowering are needed (Smith and Raven, 2012).

In the SNM literature, the success of a sustainability experiment is often defined as the increased possibility of scaling up the experiment in future (e.g. Kemp et al., 1998). This is the key challenge for sustainability experiments. As indicated in Section 1, we use a broader definition of success in this study.

An imitation of real-life conditions in so-called living labs may help sustainability experiments become successful. Such labs offer beneficial preconditions (i.e. user involvement, real-life settings and a formal evaluation) to advance transitions (Almirall and Wareham, 2008; Schliwa and McCormick, 2016).

In practice, we observe that individual experiments are not isolated events, but build on each other over time. Geels and Raven (2006) conceptualise how the local outcomes of an experiment are transformed into generic lessons by aggregation activities, in which conferences, workshops and journals and so on play a role (see Fig. 1). For these aggregation activities, intermediary actors at the community level (e.g. branch organisations) are important (Geels and Deuten, 2006). In such a 'learning trajectory' there may be an individual project that fails. Still, a failing project may constitute a positive contribution to an overall learning trajectory (Geels and Schot, 2010). 


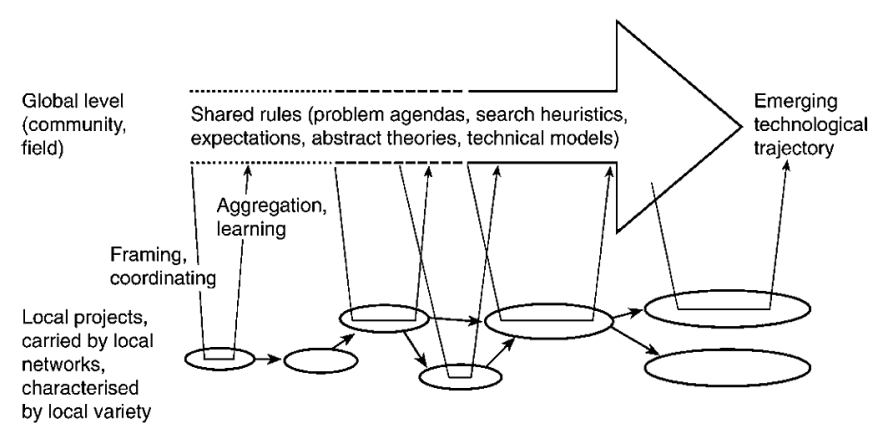

Fig. 1. Technical trajectory carried by local projects (Geels and Raven, 2006).

\section{Success factors for upscaling to regime change}

The success factors for the upscaling of sustainability experiments have been studied by transition scholars. However, their work mostly focuses on technological innovations. More in detail they focus on the success factors for the emergence of a technological niche towards a market niche (Hoogma et al., 2002; Kemp et al., 1998). Three success factors are generally recognised:

- the articulation of expectations and visions. Successful niches have visions which are: (i) shared by many actors, (ii) specific and (iii) of high quality

- building of social networks. Successful niches have (i) broad networks and (ii) deep networks.

- learning processes at various dimensions, i.e. first order learning (maintenance learning) and second order learning (reframing, or reordering of assumptions; Sterling, 2007).

In the literature, there are some indications that the upscaling of sustainability innovations is more difficult than the upscaling of innovations in general. Often, there is no relative advantage for the user (Rogers, 2003). A sustainability niche requires a protective space that allows for nurturing and experimentation (Schot and Geels, 2008). Such a niche is a space where radical innovations can develop without being subjected to the harsh selection pressures of the prevailing regime (Sengers et al., 2016). Selection pressures include technical standards and market rules (see Smith and Raven (2012) for an extensive discussion). The RIS literature includes some research related to protective spaces. The hypothesis that local nursery and adoption circumstances of experiments are crucial for their success has been formulated and tested before (Duranton and Puga, 2001).

As argued above, the geographical dimension was initially lacking in the TM and SNM literature, even though it is inherently important for explaining the success of an experiment. For this dimension, we make use of the literature on regional innovation systems.

\subsection{Regional innovation systems}

The regional innovation systems (RIS) literature offers an important insight that is relevant to our research question: geographically, innovation activity is not evenly distributed among and within countries. Spatial clustering of innovation occurs in knowledge-intensive regions where firms and research institutes profit from agglomeration economies (e.g. by matching labour demand and supply, sharing common specialised input and generic infrastructures, and gaining learning opportunities from cooperation partners and competitor, Duranton and Puga, 2004). Besides urban advantages of density in production and consumption, the learning opportunities in the cooperation structures of firms, research institutes and governments - the so-called triple helix constitutes an innovation system (Asheim and Gertler, 2006). Recently, society at large has been seen as the fourth dimension in innovation systems, as origin and adaptation of new applications increasingly stem from self-organised initiatives at individual levels that generally lack upscaling resources. In regional innovation systems, the institutional arrangements and conditions are crucial for creating an innovative and growth-oriented economic climate; yet, it is often argued that governments facilitate important conditions (in safety, funding, education, accessibility, housing and amenities), whereas firms and research organisations become members of innovative cooperation networks (Cooke et al., 2004; Chesbrough, 2003). From the RIS literature we can distil three factors that hypothetically provide an explanation for the differences between locations and regions with respect to their innovative activities. These factors are proximity, knowledge spillovers and regional capabilities.

Five dimensions of proximity may be distinguished: organisational, social, institutional, geographical and cognitive proximity (Boschma, 2005). Learning processes and innovation are facilitated by geographical proximity, as co-location fosters face-to-face contacts and reduces the risks and uncertainties in economic relations. However, other forms of proximity may reinforce local clustering of learning processes but may also imply learning relationships over larger distances. Learning in cooperation networks builds on mutual cognitive understandings: on the sharing of technologies, on market orientation, on types of business models, and on mutual trust and habits in niche markets (Boschma, 2005). In search of the optimal cognitive proximity of firms, governmental agencies and research institutes, it is necessary that there is a delicate balance in common understanding. If there is insufficient cognitive proximity, firms may be unable to learn from each other; however, if there is too much cognitive proximity, this may lead to lock-out from community-external developments (Nooteboom, 2000). Other forms of proximity may coincide with this, like social network relatedness, institutional similarities (both formally and informally defined; see Cortinovis et al., 2017) or organisational relatedness (in terms of ownership, the business models applied and legal forms of organisation). Invention and learning processes can profit from other types of proximity in addition to or coinciding with geographical proximity (Cooke et al., 2004; Asheim and Gertler, 2006). This builds trust.

Knowledge spillovers are also important; these are the larger opportunities of productive knowledge exchange among firms and research institutes in dense, mostly urban areas (Jaffe et al., 1993). These spillovers are tacit, and therefore geographical proximity facilitating face-to-face contact is important (van Oort and Bosma, 2012). Similar to the proximity conceptualisation, this tacit knowledge is often created by social learning, i.e. by interactions between firms, knowledge institutions and government, and also by interactions between producers and users (Asheim and Gertler, 2006). Research emphasises that specific knowledge is neither equally accessible nor equally relevant to economic actors (Nooteboom, 2000).

Finally, regional capabilities are important for learning and innovation. These capabilities are formed by the general human and physical resources, and by the knowledge and skill base that are embedded in their industrial and institutional structure. These capabilities are difficult to imitate by other regions as they often build on previous stocks and diversification of the skill bases present in these regions (Neffke et al., 2011). The regional capability to produce and use knowledge are key to success (Cooke et al., 2004), as it contributes to developing effective organisations, facilitates collaboration between firms, governments and knowledge institutes and increasingly also between these stakeholders and 
society at large, and contributes to the upgrading skills needed for innovative and productive activities. Knowledge-based institutional assets are closely related to these capabilities (Gertler and Wolfe, 2004).

These factors from the RIS literature may help us find geographically explicit success factors for sustainability experiments, which we can use as the basis for our empirical work. This is described in Section 2.4 below.

\subsection{Towards the combination of factors from TM and RIS}

The combination of TM and RIS literature allows us to better understand the success factors for sustainability experiments in their geographical contexts. Since these two bodies of literature represent rather distinct lines of research, combining them is not an easy task. TM literature is based on the multi-level perspective, whereas RIS literature is primarily based on the theory of competitive advantage of regions. However, two studies have recently been undertaken that may be regarded as the first step towards the combination of TM and RIS literature. One deals with the geography of transitions (Hansen and Coenen, 2014) and the other discusses sustainability experiments (Sengers et al., 2016).

Hansen and Coenen (2014) reviewed the literature on the geography of transitions. They conclude that the geographical context and scale matter in sustainability transitions, but there is little knowledge on how context and scale matter. In a literature review on the role of experiments in sustainability transitions, Sengers et al. conclude that the way in which experiments are embedded (or fail to become embedded) in local contexts such as cities and regions deserves further exploration. The authors raise the question how "proximities in local and regional networks, infrastructures, resource endowments, political agendas, market structures, cultural settings and so on influence the form and outcome of experimental initiatives?" (Sengers et al., 2016). Our research aims to address these gaps in our understanding and to take the next step in the integration of both research fields. However, we are not aiming at a full integration of both theories. Rather, we attempt only to merge the factors from TM that explain the upscaling of sustainability experiments with the factors from RIS that explain the differences between regions in innovative activities.

\subsection{The combined factors from TM and RIS}

In Section 2.1-2.3 we discussed the theoretical background to our research. This is formed by complementary insights from the TM/SNM literature, the RIS literature and other literature on success factors. We are now able to combine these to construct two basic building blocks of our conceptual framework.

\subsubsection{A longlist of success factors}

The first building block of our conceptual framework is presented in Table 1. This is a longlist of success factors for sustainability experimentation. We have constructed seven groups of factors found in the literature. The success factors from TM/SNM literature and RIS literature have specific meanings. The factors from TM/SNM literature deal with factors that promote upscaling; in most cases this concerns upscaling from a technological niche towards a market niche (Geels and Schot, 2010). The factors from RIS literature deal with factors explaining the differences between regions in innovative activities.

The success factors from the TM literature are geographically implicit, and the RIS literature helps to make them geographically explicit. This combination results in 7 groups of factors, which are explained in detail below.
1. Vision factors. Kemp et al. (1998) mention the importance of creating a sectoral or societal long-term vision. This would help to coordinate the strategies of the stakeholders involved. Hansen and Coenen (2014) summarise a large number of studies emphasizing the important role of urban and regional visions. They also mention that local economic specialisations promote the innovations necessary for transitions. This specialisation is often the starting point for a regional policy agenda. We conclude that vision factors are expected to be mainly economically and geographically important on a local and regional scale.

2. Network factors. Kemp et al. (1998) state that new social networks need to be formed during niche formation. In addition, Boschma (2005) shows the importance of those networks as vehicles of knowledge creation and diffusion. In his work, various types of proximities are important. He shows that social networks are not necessarily localised. On the other hand, geographical proximity brings people together and facilitates the exchange of tacit knowledge. These face-to-face interactions are also mentioned by Asheim and Gertler (2006). We conclude that network factors are expected to be important in various forms of proximity, and that a regional scale might be helpful especially for face-to-face interactions and for the exchange of tacit knowledge.

3. Learning factors. Kemp et al. (1998) mention that experiments should enact a broad learning process. In the RIS literature, the importance of learning is addressed in various ways. Asheim and Gertler (2006) combine two major features of the innovation process: the importance of tacit knowledge and the growing importance of a socially organised learning process. These features make apparent why the regional geography matters so much. In addition, the authors mention nongeographical learning factors. Other groups of the factors in Table 1 may also contribute to learning: e.g. network factors and demographic factors (esp. regional capabilities). We conclude that learning factors are expected to be important in various ways, often in a localised but also in a non-localised manner.

4. Cultural factors. In the sparse TM literature on cultural factors, there is a noteworthy study of the regional growth differentials in German photovoltaic markets (summarised in Truffer and Coenen, 2012). This study showed that the diffusion of photovoltaic energy in Germany was promoted by a local cooperative culture (although there were other factors at play, too). In the RIS literature, Asheim and Gertler (2006) emphasise trust-based relations in the cooperation between firms and customers in regional clusters. We conclude that cultural factors may be important, often on a regional scale, perhaps as an attribute of regional networks.

5. Government factors. Government factors are almost absent in both the TM and the RIS literature. Only few specific policy measures are mentioned. We conclude that government factors are unclear, and that they may be important on various geographical scales.

6. Demographic factors. These factors are not mentioned in the TM literature. In the RIS literature, Maskell and Malmberg (1999) discuss the regional capabilities for learning and innovation. In general innovation literature Rogers (2003) emphasises the importance of the attitude of users towards risks and the presence of innovators and early adopters for the diffusion of innovations.

7. Other factors. This is a mixture of factors mentioned by various researchers, see Table 1 . We add to this that in general innovation literature von Hippel (1986) shows the importance of lead users. Lead users are familiar with future conditions, and may 
Table 1

Longlist of success factors from the TM and RIS literature.

\begin{tabular}{|c|c|c|}
\hline $\begin{array}{l}\text { Groups of factors for our } \\
\text { research }\end{array}$ & Success factors from the TM/SNM literature & Factors from the RIS literature \\
\hline Vision factors & Expectations \& vision (Kemp et al., 1998) & $\begin{array}{l}\text { Urban and regional visions, Regional specialisation (Hansen and Coenen, } \\
\text { 2014) }\end{array}$ \\
\hline \multirow[t]{2}{*}{ Local/regional network factors } & Social networks (Kemp et al., 1998) & Proximity between regional triple helix actors (Boschma, 2005) \\
\hline & Rootedness of networks (Dewald and Truffer, 2012) & Face to face interactions (Asheim and Gertler, 2006) \\
\hline \multirow[t]{3}{*}{ Learning factors } & Learning (Kemp et al., 1998) & Knowledge spillovers (van Oort and Bosma, 2012) \\
\hline & & Social learning (Asheim and Gertler, 2006) \\
\hline & & Skill base (Neffke et al., 2011) \\
\hline Cultural factors & Cooperative culture (Truffer and Coenen, 2012) & $\begin{array}{l}\text { Trust, informal institutions (Asheim and Gertler, 2006; Cortinovis et al., } \\
\text { 2017) }\end{array}$ \\
\hline Government factors & Room for experimentation (Loorbach, 2007) & Institutions, availability of funding, (Cooke et al., 1997) \\
\hline Demographic factors & & $\begin{array}{l}\text { Regional capabilities, e.g. human resources (Maskell and Malmberg, 1999) } \\
\text { Creative people (Florida, 2002) }\end{array}$ \\
\hline \multirow[t]{3}{*}{ Other factors } & $\begin{array}{l}\text { Competence (e.g. entrepreneurship) of the actors (Loorbach, } \\
\text { 2007) }\end{array}$ & \\
\hline & The set-up of the experiment (Hoogma et al., 2002) & \\
\hline & Motivation of users (Seyfang and Smith, 2007) & \\
\hline
\end{tabular}

thus play an important role in the upscaling of sustainability experiments.

We aggregated the factors found in the literature to 7 groups of factors, which are mentioned in the first column in Table 1. We used these factors directly in our empirical research.

\subsubsection{A framework of experiments in distinctive favourite habitats}

The second building block of our conceptual framework is presented in Fig. 2. We observe that a large variety of sustainability experiments have been carried out in Europe. These experiments differ in several aspects, including goals, themes, type of knowledge needed, actors involved, and geographical context. This is illustrated in the TM as well as the RIS literature. Sengers et al. (2016) describe six types of sustainability experiments. Tödtling and Trippl (2005) argue that there are different types of regions with distinctive preconditions for innovation. In order to answer our research question, we need to develop a conceptual framework that allows us to critically examine our hypothesis that there are various types of sustainability experiments, and that they each have distinctive favourite habitats, each with specific success factors. We introduce the habitat concept here in order to suggest that an experiment is carried out in co-evolution with its geographical context. The habitat may promote or hamper the success of an experiment. An experiment is a member of an archetypical habitat, but regions and cities can host several types of habitats simultaneously. The dimensions in our conceptual framework should cover the large variety of experiments and success factors. We extract two main dimensions from the literature, which are presented in Fig. 2 as perpendicular to each other.

From the SNM literature, we hypothesise that there is a great contrast between experiments that are 'guided' (e.g. by visioning, see Kemp et al., 1998) and 'grassroots' experiments (Seyfang and Smith, 2007). This forms the vertical dimension of our framework. We call this dimension the governance axis, in line of the definition of governance by Bevir (2013), who uses governance in connection with governments, firms, networks and the grassroots movement (Bevir, 2013). Guided experiments show a clear governance, e.g. by an individual actor such as a firm or a government, and show a clear protocol for learning. There is no clear leadership in grassroots experiments. Their organisational form is diverse and may consist of voluntary associations, co-ops and informal

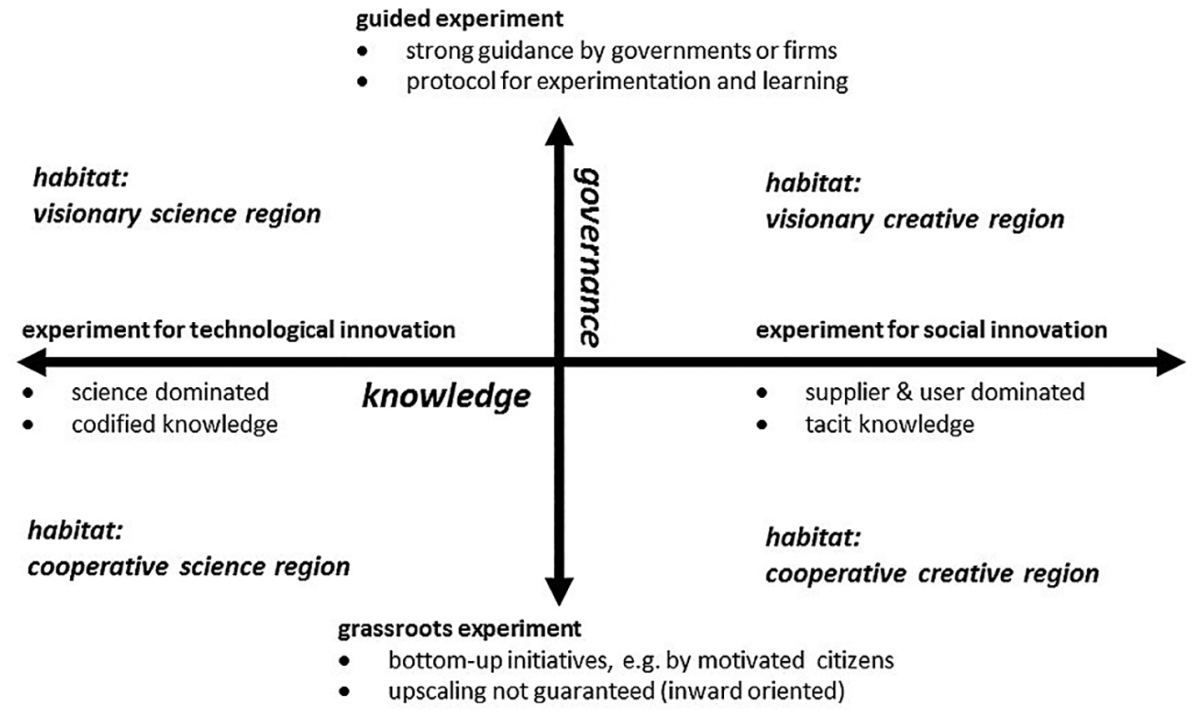

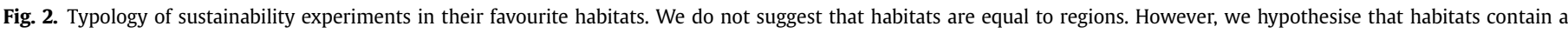
configuration of success factors mainly on a local and regional scale. 
community groups. They are often unstructured and do not leave formally documented institutional learning (Seyfang and Smith, 2007).

From the RIS literature, we hypothesise that experiments focused on technological innovation are different from experiments primarily focused on social innovation. This contrast forms the horizontal dimension of our framework. We call this dimension the knowledge axis because the knowledge involved varies widely.

Experiments for technological innovation deal with technological inventions. They are often science-dominated and use codified knowledge (Malerba, 2005). Codified knowledge may be easy to transfer to subsequent experiments. Experiments for social innovation deal with new ways of finding solutions for societal challenges; they also deal with behavioural change. They are often supplierdominated and use tacit knowledge (Moulaert and Nussbaumer, 2005). Part of this knowledge may consist of symbolic knowledge, which is strongly tied to habits and norms of social groups (Asheim et al., 2007), and may thus be difficult to transfer to subsequent experiments.

We have now constructed a framework with four types of experiments. As indicated in Section 1, we suggest that experimentation is carried out in co-evolution with its habitat. We hypothesise that the habitat of an experiment may be regarded as a configuration of contextual factors which are mainly embedded locally or regionally. The various types of experiments each have their hypothesised favourite habitat. We found some indications of habitats in the literature. On the vertical axis of Fig. 2, Cooke (1992) discriminated 'dirigiste' regions (with high coordination and strong specialisation) from 'grassroots' regions (with low coordination and weak specialisation). On the horizontal axis, Spencer (2015) showed that neighbourhoods with science-based innovations have different characteristics than neighbourhoods with creativitybased innovations. We hypothesise that these two habitat dimensions span four typical habitats, located in the quadrants of this conceptual framework (see Fig. 2).

We would like to emphasise that the two axes deal primarily with experiments rather than regions. To give an example: the habitat 'visionary science region' is hypothesised to be favourable to guided experiments for technological innovation. This kind of habitat may be found on and around a technologically-oriented campus. This habitat may for example be present in Silicon Valley. Here, the exchange of technological knowledge among firms constitutes a key element of the 'innovative milieu' that enhances innovation (Kenney, 2003). On the other hand, the habitat 'cooperative creative region' may be a very different milieu, and may perhaps be found around a city or region with many grassroots initiatives and a cooperative culture. For example, this habitat may be present in the village of Totnes, an 'alternative milieu' and a transition town in the South West of the UK (Longhurst, 2015).

It should also be noted that the ends of the axes are formed by two analytically distinct dimensions of 'governance' and 'knowledge'. The ends of an axis are not necessarily each other's opposites. Also, these dimensions have an analytical purpose. In reality, we expect to find many mixed characteristics.

We are now able to combine the two building blocks of our conceptual framework mentioned above. We hypothesise that the four habitats each contain their specific success factors. Each habitat may contain a specific subset of factors, selected from the longlist as presented in Table 1.

\section{Material and methods}

Our research question leads to examining the success factors, barriers and upscaling mechanisms of European sustainability experiments. Since we are one of the first to carry out an empirical study with such a broad scope in the field of the geography of transitions, we need a research design with an exploratory character. A qualitative research with semi-structured interviews (Bryman, 2012) is adequate for this purpose. Our research question contains two aspects, which both have distinct methodological consequences:

a. We wish to know whether there are important success factors that have not yet been mentioned in the literature. For this purpose we used open questions.

b. We wish to develop a more detailed understanding of the factors identified in the literature. For this purpose we used semiopen questions.

Information was collected through telephone interviews, since we used open questions and since we wished to explain some concepts to the respondents. The main steps in our research were (i) formulating the research question and developing the questionnaire, (ii) selecting of the cases, (iii) interviewing and (iv) analysing the data to find the answers to the research question.

\subsection{The questionnaire}

The questionnaire contained the following elements:

a. Definition of success.

In this research, our definition of success has two dimensions: a short-term and a long-term dimension (see Section 1). Our research question, however, focuses on the long-term dimension. In the questionnaire, we asked the respondents how they define success in their project. We asked this in an open question (we did not give any information about a short-term and long-term dimension in advance).

We are interested in the success factors contributing to a longterm regime change, and therefore we asked the respondents to focus on these factors in the remainder of the interview.

b. The three most important success factors.

Our survey has an exploratory character, which is why we asked respondents in an open question to indicate the three most important success factors.

c. Rating of habitat factors.

We derived 6 groups of habitat factors from the literature (see Table 1). We asked for ratings of the habitat factors on a fivepoint scale.

d. Habitat factors in detail.

In semi-open questions we asked respondents to suggest more detailed success factors for the 7 groups of factors mentioned in the first column of Table 1 . We were also interested in the geographical scale of the success factors (from local to global).

e. Barriers.

In an open question we asked the interviewees to indicate the three most important barriers.

f. Upscaling mechanisms.

We asked for information on the links between the previous and the following experiment in the upscaling trajectory. We also asked the interviewees to indicate activities in the project aimed at promoting future upscaling.

\subsection{Case selection}

At the time of data collection, numerous sustainability experiments were being carried out in Europe. To select relevant cases, our rationale was to incorporate the various types of experiments from our conceptual framework (see Fig. 2), various themes (agri- 
food, mobility and energy), in urban as well as rural areas in various EU countries. For the further case selection, we used three criteria:

a. The sustainability criterion. The experiment should be focused on the transformation of the way in which human needs are met (Sengers et al., 2016). In practice, we focused on experiments regarding energy (e.g. smart grids), mobility (e.g. sharing systems for electrical vehicles) and agri-food (e.g. regionalised food systems or urban farming); Fig. 4 presents some typical examples of sustainability experiments. Sustainability experiments are also goal-oriented; consequently, we were interested in selecting purposive interventions that explicitly seek to capture new forms of learning or experience (Castán Broto and Bulkeley, 2013).

b. The experimental criterion. The innovation should be in the experimentation phase of a transition (Rotmans et al., 2001). We translated this into a practical criterion: there should be a prototype available. This prototype might have been tested a few times, but there should still be uncertainty whether it will work in real life and whether it will be embedded in the regime. This criterion is also useful to make a distinction between experiments and the large group of sustainability initiatives.

c. The living lab criterion. We made this criterion more explicit. We asked the respondents to indicate if users are involved in the experiment, in a real-life of semi real-life setting.

All cases included in this study met these three criteria.

\subsection{Interviewing}

We interviewed people with sufficient knowledge of the experiment, of the actors involved and of the local and regional context. Often this was the project leader, business manager or owner. We asked questions on success factors, barriers, upscaling trajectories and specific activities aimed at upscaling the experiment. The interviews lasted approximately $30 \mathrm{~min}$.

\subsection{Data analysis}

All the data on success factors, barriers and upscaling mechanisms were coded manually. We carried out two analyses to find groups of respondents with a contrast in success factors:

a. We compared the guided experiments with the grassroots experiments, and the experiments aimed at technological innovation with the experiments aimed at social innovation

b. We compared the cornerstones of our framework: the success factors of experiments within the quadrants. In this analysis we did not incorporate the experiments that were a mixture of technological and social innovation (see Fig. 3).

The second analysis provided the strongest contrast (i.e. the differences in the factors mentioned were large). Each resulting quadrant has a small number of cases (see Fig. 3), varying between 6 and 14. Due to the low frequencies in the cells, it was not possible to evaluate these outcomes statistically with a chi-square test.

\subsection{Description of the sample}

Our sample was selected from all the sustainability experiments in Europe. The exact number of sustainability experiments in Europe is unknown. Castán Broto and Bulkeley (2013) found 159 climate change experiments in European cities. The European Network of Living Labs found approximately 400 labs in the past 9 years, but only some of these are related to sustainability. The

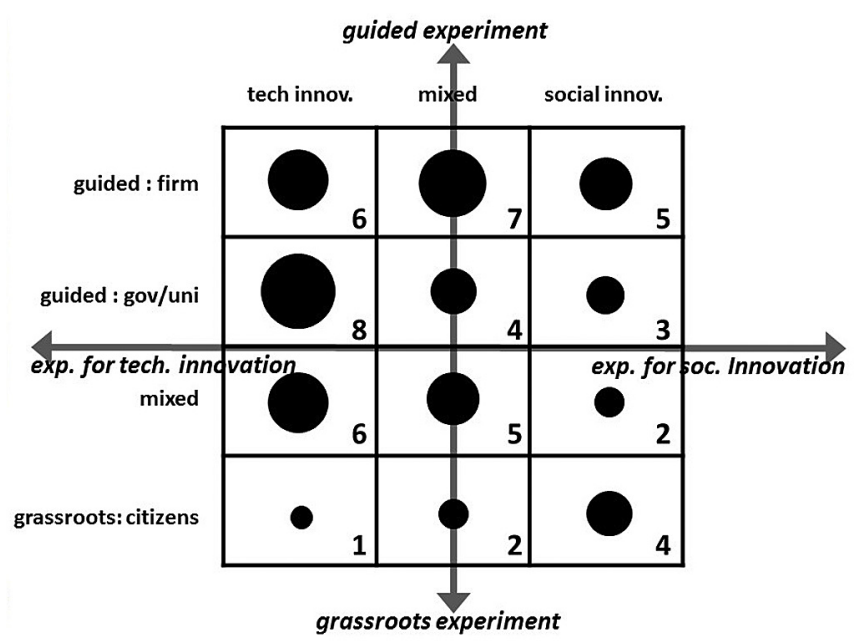

Fig. 3. Distribution of the research sample in our framework. The numbers represent the number of cases in our sample. Gov/uni stands for government or university.

grassroots initiatives in Europe are probably numerous, but these are difficult to find. About 400 grassroots food initiatives were found in the Italian province of Lombardy alone (Grasseni, 2014); some of these may be regarded as experiments.

Our sample contains 56 cases, distributed throughout 14 European countries (see Appendix). These cases were selected from existing European databases. We also used websites from the individual cases. Our sample contains the various types of experiments from our hypothetical framework (see Fig. 3), although there is an underrepresentation of the grassroots experiments $(n=7)$, since it was difficult to find respondents for this group.

In our sample, $46 \%$ of the cases are involved in energy innovations, $38 \%$ in mobility innovations and $16 \%$ in food innovations. About 60\% are located in urban areas, 20\% in rural areas and 20\% in both (some experiments were carried out in various locations).

Fig. 4 presents some typical examples of our sample. The energy experiments often deal with smart grids, the mobility experiments deal with charging and sharing systems for electrical vehicles, and the agri-food experiments deal with regionalised food systems or urban farming.

In our sample we also collected experiments for social innovation. These experiments can be divided into two types. The first type involves technological prototypes, but the experiment is concerned with social or behavioural aspects, e.g. an experiment

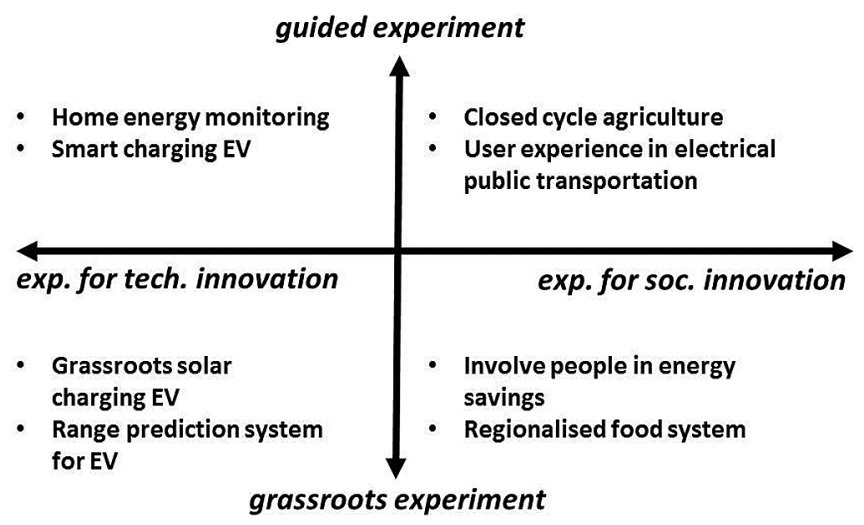

Fig. 4. Some typical examples of sustainability experiments in our sample. EV stands for electrical vehicles. 
Table 2

The definition of success by respondents. ${ }^{1}$ Indicated are the three answers mentioned most often, in \% of the respondents. The respondents were allowed to include more than one definition in their answer.

1. Possibility for upscaling (48\%)

2. Technical performance of the innovation $(27 \%)$

3. Usability (16\%)

dealing with user experience in an electric public transportation system (see Fig. 4). The respondents often classified these kinds of experiments as a mixed form of technological and social innovations. The second type deals with prototypes of a new method or procedure, e.g. an experiment with a new method for involving people in energy savings (see Fig. 4).

\section{Findings}

Our research question is to find success factors, barriers and upscaling mechanisms for sustainability experiments. Below we present our findings.

\subsection{Success factors}

\subsubsection{Definition of success}

In this research our definition of success has two dimensions: the short term and the long term (see Section 1). It is important to see how our respondents define success; Table 2 presents their ideas.

The respondents mentioned upscaling most (i.e. the long-term dimension of our definition of success, see Section 2.1). However, an interesting finding is that upscaling was often mentioned together with a different aspect, and particularly with technical performance. This relates to the short-term dimension of our definition of success. A lot of respondents had the opinion that the long-term and the short-term dimension of success are interlinked.

Only $14 \%$ of the respondents mentioned profitability. This indicates that we are dealing with projects that are still in the take-off phase, and not yet in the breakthrough phase; after all, in the breakthrough phase the market introduction becomes more important (see Section 2.1). No large variations were found in the definition of success for the various types of experiments (see Fig. 2). This is remarkable, since it may be expected that upscaling is less important for grassroots experiments, as such experiments are often inward-oriented (de Moor, 2013).

\subsubsection{The three most important success factors}

User involvement was mentioned most frequently as the most important factor (Table 3). On the one hand, this is no surprise, as we are focusing on living labs. On the other hand, it is surprising, as this factor is almost absent in TM literature. Rotmans et al. (2001) mention the participation of actors in general. This may include users, but he also points towards other actors (e.g. companies and governments). On average, user involvement was rated 3.9 on a five-point scale in our sample.

Interestingly, Table 3 shows a mixture of project-internal factors and habitat factors. Some factors may belong to both groups: learning involves learning from the user, i.e. a project-internal factor, but learning may also relate to social learning and dissemination, i.e. a habitat factor. Vision might have to do with a project vision, which is a project-internal factor, or with the existence of a

\footnotetext{
1 All the findings in this section concern all the respondents in the sample $(\mathrm{n}=$ 54).
}

regional vision, which is a habitat factor. However, our results show that a vision and learning are particularly important in the habitat.

\subsubsection{Importance of habitat factors}

From the literature we derived 6 groups of habitat factors (see Table 1). Fig. 5 shows their rating. The four most important factors are also mentioned in Table 3. One factor is less important: the regional demographics. However, we have to be aware that some factors may be interrelated, e.g. culture and regional networks (see Section 2.4).

\subsubsection{Habitat factors in detail}

We have searched for more detail in the six groups of habitat factors because this may provide the stakeholders with more relevant information about ways of improving the success of their experiments. The results show the following:

- In relation to vision, the availability of a regional vision is more important than a national or global vision.

- For regional networks, it is important that citizen groups and knowledge institutes are involved in these networks

- With regard to learning, important factors include (i) learning from the user by the team, (ii) social learning and (iii) second order learning.

- In relation to the local and regional government, funding is often mentioned as important. Moreover, the government can create an area with fewer regulations where experimentation is allowed. For new inventions entering society, the government can make new regulations.

- For cultural factors, the qualities trust, openness and cooperativeness are mentioned.

- With regard to the regional demographics, the regional knowledge and skills are mentioned.

\subsubsection{Distinctive favourite habitats}

Our hypothesis is that the various types of experiments have distinctive favourite habitats, each with their specific success factors. We found some indications for this variation between the types of experiments (Fig. 6).

These are the results of a semi-open question. For every group of factors (see Table 1), respondents were asked to indicate the most important one. This figure only displays the factors that were mentioned by $50 \%$ or more of the respondents for that habitat.

As shown in Fig. 6, we found some contrast in success factors between the quadrants. In particular, we found that some habitats are more pronounced in their visibility than others:

- The existence of a regional vision is mentioned in the upper quadrants. This directly relates to the habitats 'visionary science region' and 'visionary creative region'. A regional vision may give a strong guidance, and may form a habitat which is favourable for guided experiments

- The availability of funding is perceived as important in the 'visionary science region' and in the 'cooperative science region', i.e. in the habitats favourable for technological innovation. This success factor was also mentioned by Cooke et al. (1997), also in relation to technological innovations.

- The regional knowledge and skills are considered important in the quadrants on the left. This factor belongs to the group of regional demographic factors, and was not of eminent importance for the entire sample; however, it was important for experiments on technological innovation. Moreover, this factor is emphasised in the mainstream RIS literature, which 
Table 3

Success factors, classified as project-internal and habitat factors. Indicated are the answers mentioned most often, in \% of respondents (open question).

\begin{tabular}{ll}
\hline Success factor & $\begin{array}{l}\text { Project-internal or } \\
\text { habitat }\end{array}$ \\
\hline $\begin{array}{l}\text { 1. User involvement, esp. number of users, user experience, } \\
\text { user engagement (33\%). }\end{array}$ & \\
$\begin{array}{l}\text { 2. Regional } \\
\text { (23\%) }\end{array}$ & Hetwork, esp. cooperation between partners \\
3. Profitability, esp. business case, costs (21\%) & Project-internal \\
$\begin{array}{l}\text { 4. Government, esp. funding by local/regional government, } \\
\text { new regulation or }\end{array}$ & \\
$\begin{array}{l}\text { absence of existing regulation by local/regional } \\
\text { government ( } 21 \%)\end{array}$ & \\
5. Technical quality of the invention (19\%) & Project-internal \\
6. Learning, esp. dissemination (16\%) & Habitat \\
7. Vision, esp. a regional vision (10\%) & Habitat \\
\hline
\end{tabular}

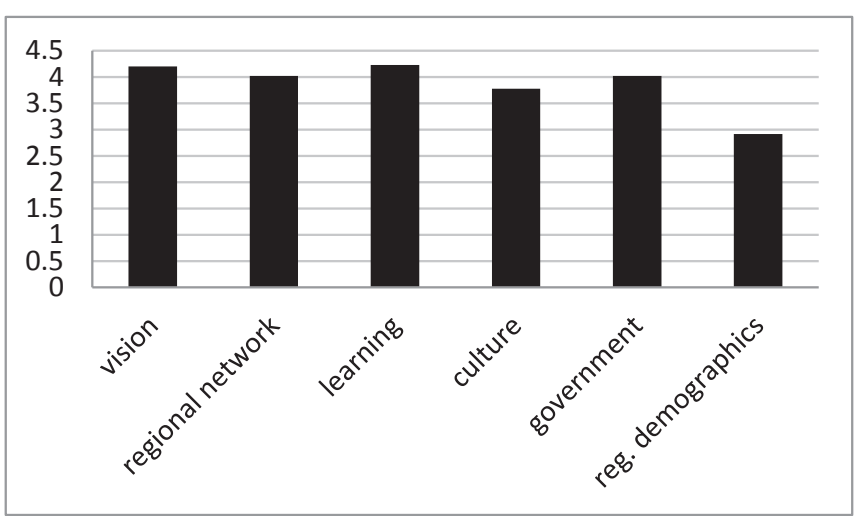

Fig. 5. The importance of habitat factors for success. Average rating by respondents on a five-point scale (semi-open questions).

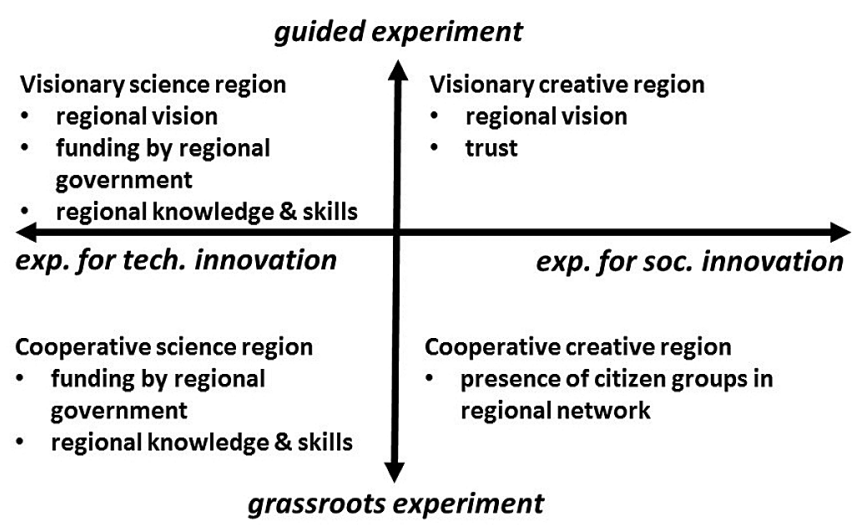

Fig. 6. Dominant success factors for distinctive habitats.

predominantly deals with technological innovations. Therefore, this finding supports our hypothesis.

- Trust is mentioned in the 'visionary creative region'. We hypothesised that trust is an important success factor, which is, however, not restricted to this specific habitat.

- The presence of citizen groups in the regional network is mentioned in the 'cooperative creative region'. It is not a

\footnotetext{
${ }^{2}$ In Sections 4 and 5, where the term 'regional' is used in combination with network, vision or context, this should be read as 'local and regional'.
}

surprise that the presence of citizen groups as such is mentioned, since we are dealing here with grassroots innovations. This refers directly to the literature on grassroots sustainability innovations, where experiments are carried out by citizen groups, e.g. co-ops and informal community groups (Seyfang and Smith, 2007). However, our findings suggest that these groups should be part of a regional network to become successful.

This contrast confirms our main hypothesis that the various types of experiments each have their distinctive favourite habitats, each with their specific success factors.

\subsection{Barriers}

We are also interested in barriers to success, mainly because these may be the opposite of success factors, and because they are relevant in the perspective of upscaling and regime change. The regime may pose barriers to the diffusion of niche innovations (Geels and Schot, 2010). Table 4 presents the most important barriers. Most of the barriers are the reverse of a success factor (the funding, the technical quality of the invention and regulations - or their absence). The third and fourth factors in this list indicate that the niches already meet some first-regime barriers (see Section 2.1). The fourth factor mentions government regulation; note that this deals mainly with existing regulation as a barrier to experimentation.

\subsection{Upscaling mechanisms}

We have already indicated above that upscaling is a key challenge for sustainability experiments. Often, the experiments are part of an upscaling trajectory. In our questionnaire we explored this issue.

In our survey, we mapped the geographical upscaling trajectory (see Appendix). This trajectory is formed by the locations of the linked previous and the following experiments, and the links between these locations. Our results show that $71 \%$ of the sample are part of an upscaling trajectory. Two geographical patterns can be observed. The first deals with upscaling in the same location. This is sometimes called regional expansion (Jolly et al., 2012), and 50\% of the experiments follow this pattern. The second pattern deals with upscaling somewhere else, either in the same region or in another global region. This is sometimes called replication or scaling out (Jolly et al., 2012). Our results show that $47 \%$ are replicated in another place in Europe. The map also indicates that replication distances are not very great: replication occurs mainly within a country or between adjacent countries. Only one experiment is replicated outside Europe.

"To help upscaling, we made an evaluation of the project, to learn what went well and what went wrong" (quote from one of our respondents)

To promote future upscaling, dedicated activities are carried out. Learning is important, as is shown by the quote above. Respondents often mentioned the following other activities aimed at upscaling: disseminating the 'lessons learned', networking, demonstrating and marketing. 
Table 4

The most important barriers to success. Indicated are the answers mentioned most often (in \% of respondents).

1. Shortage of money and funding (38\%)

2. Insufficient technical quality of the invention (23\%)

3. Resistance and vested interests (21\%)

4. Government: existing regulation, absence of new regulation (20\%)

\section{Discussion}

The main aim guiding this research was to find success factors, barriers and upscaling mechanisms of European sustainability experiments in their geographical context. The main finding is that the success factors are mostly embedded in the local and regional habitat.

We have two points for discussion: the usefulness of the habitat concept and the short-term versus long-term dimension of success.

The first point for discussion is the usefulness of the habitat concept. We introduced the habitat concept to suggest that experimentation is carried out in co-evolution with its geographical context. We have identified three ways in which the habitat concept is useful.

First, the concept allows us to discriminate project-internal factors from contextual factors (see Table 3 ).

Second, as a result of this research we have found that a habitat could be regarded as a configuration of contextual factors that are mainly locally or regionally embedded. This relates to the factors 'vision', 'regional networks', 'government' and demographics'. These factors probably do not coincide geographically, but they are all localised mainly on the local and regional scale, as is shown in our empirical results. However, for some factors it is uncertain on which scale they are localised. This is the case for the cultural and the learning factors. These factors may also be important on higher scale levels. Also, the often mentioned factor "funding by local/ regional government" may have its origin in European funds. With these results on factors and scales we address gaps in our understanding on the geography of transitions as indicated by Hansen and Coenen (2014). They raise the question how context and scale matter in sustainability transitions. We conclude that habitats do not have to coincide with regions, but they do have a strong regional focus. Furthermore, we suggest that habitats may overlap in a geographical sense. For example, various types of experiments may be carried out in one particular large city, each with their own distinctive favourite habitats.

Third, the usability of habitat concept would increase if we would be able to discriminate distinct favourite habitats for various types of experiments. We found some indications for this to be the case, but this was based on a small sample.

The second point for discussion is the short-term versus longterm dimension of success. We have included both dimensions in our definition of success (Section 1). Our findings suggest that these dimensions are probably interlinked (Section 4.1). In the transition literature is indicated that experiments that fail in the short term could still be qualified as successful in the long term, since they could contribute to global upscaling and regime change (see for instance Seyfang and Smith, 2007). However, our respondents did not indicate that success can be achieved by learning from failures. The only aspect of learning they mention is the importance of the dissemination of learning experiences (Table 3 ). This may be regarded as an important precondition for upscaling (Geels and Raven, 2006).

\section{Conclusions}

Our main conclusions are:
- The most important habitat factors are: regional networks, policy instruments of the local and regional government, the dissemination of learning experiences and a regional vision.

- In addition to the habitat factors, we found that project-internal factors are also important for success, especially the factor 'user involvement'. This factor is mostly ignored thus far in transition studies.

- Shortage of money and funding is considered the most important barrier.

- Almost three quarters of the experiments are part of an upscaling trajectory, either in the same place or as a replication from experiments in different places in Europe.

With these results we address gaps in our understanding of the geography of transitions as indicated in Section 2.3. Our contribution to this emerging field (based on TM and RIS literature) is that we now have articulated how the geographical context and scale matters in sustainability experimentation. However, we are aware that our sample was small. For example, we lack respondents from southern and eastern Europe.

Our findings are consistent with previous findings in the TM and RIS literature, although some factors were found to be understated in the literature (e.g. the role of the local and regional government).

The findings of this research allow us to articulate some important policy implications:

- Habitat factors are important for the success of experiments. Policymakers should be aware that it is possible to enhance habitats, e.g. by creating regional networks. In these networks, entrepreneurs, users, civil servants from the local and regional government as well as other regional partners should work actively together to make sustainability experiments more successful.

- The local and regional government may play an important role in improving the habitat. For example, the government could create a location for experimentation in which there are fewer regulations. In addition, the government could draw up new regulations or fund experiments. Finally, the government often also contributes to developing a vision and regional networks. This important government role is absent in the current TM and RIS literature. Our finding may confirm that sustainability innovations require more nurturing in protective spaces than innovations in general (see Section 2.1).

- The introduction of professional practices for experimentation may greatly improve upscaling. These practises may for example deal with instruments and techniques to involve users, to disseminate learning experiences, and so on. Some attempts have been made to develop methodologies for sustainability experimentation, e.g. in the European Network of Living Labs, but still a large number of experiments fail. In this research we hope to contribute to the development and implementation of more professional methods.

We found some indication that various experiments have their distinctive favourite habitats. However, more research is needed to understand how different habitats facilitate different types of experiments, and where to find these habitats in real life. Further research is also needed on the success factors and on possible ways to influence these. It is important to know which factors are essential, and which factors merely have a positive influence, as well as which factors can be influenced in the short term, which are relatively stable, and which may be self-reinforcing. We are greatly motivated to shine more light on this in future. 


\section{Acknowledgements}

We would like to express our gratitude to the Provinces of Utrecht and Gelderland, both in The Netherlands, for their financial support for this research. In addition, we would like to thank a group of students from Utrecht University for their help with the data collection. Finally, we would like to thank four anonymous reviewers for their valuable comments on an earlier version of this paper.

\section{Appendix}

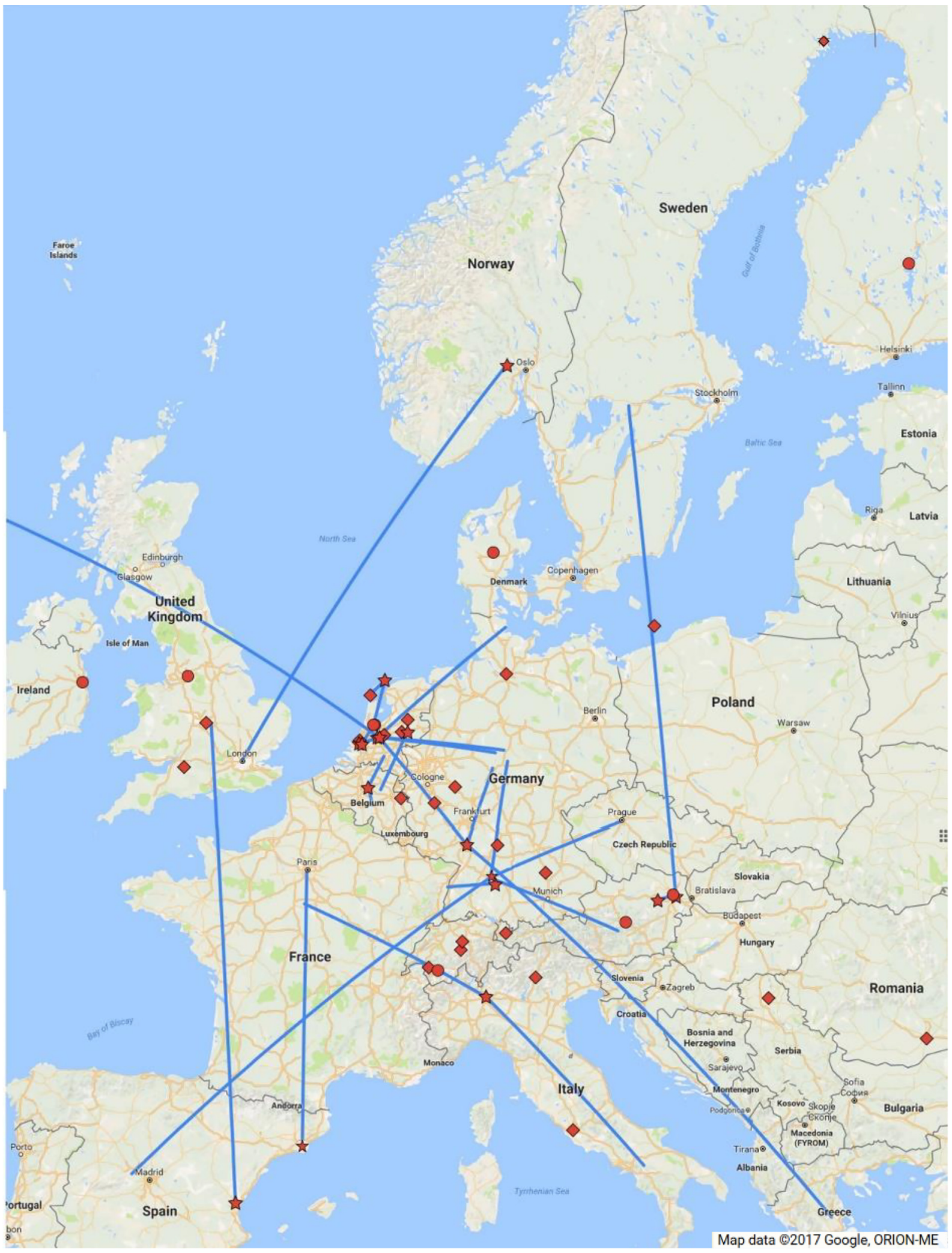


The locations and the geographical upscaling trajectories of the experiments in our sample. The cubes indicate experiments without upscaling, and the circles indicate experiments with upscaling in the same location. The stars indicate experiments with upscaling to other locations (the lines represent the trajectories with previous as well as next experiments).

\section{References}

Almirall, E., Wareham, J., 2008. Living labs and open innovation: roles and applicability. Electron. J. Virtual Organ. Netw. 10. "Special Issue on Living Labs".

Asheim, B.T., Gertler, M.S., 2006. The geography of innovation: regional innovation systems. In: The Oxford Handbook of Innovation, pp. 291-317.

Asheim, B.T., Coenen, L., Moodysson, J., Vang, J., 2007. Regional innovation policy. Int. J. Entrepreneursh. Innov. Manag. 7 (2-5), 140-155.

Barca, F., McCann, P., Rodríguez-Pose, A., 2012. The case for regional development intervention: place-based versus place-neutral approaches. J. Reg. Sci. 52 $134-152$.

Bevir, M., 2013. Governance: a Very Short Introduction. Oxford University Press, Oxford, UK.

Boschma, R., 2005. Proximity and innovation: a critical assessment. Reg. Stud. 39 (1), 61-74.

Bryman, A., 2012. Social Research Methods, fourth ed. Oxford University Press, Oxford.

Castán Broto, V., Bulkeley, H., 2013. A survey of urban climate change experiments in 100 cities. Glob. Environ. Change Hum. Policy Dimens. 23 (1), 92-102.

Chesbrough, H., 2003. Open Innovation: the New Imperative for Creating and Profiting from Technology. Harvard Business School Publishing, Boston.

Cooke, P., 1992. Regional innovation systems: competitive regulation in the new Europe. Geoforum 23, 365-382.

Cooke, P., Gomez Uranga, M., Etxebarria, G., 1997. Regional innovation systems: institutional and organisational dimensions. Res. Policy 26 (4-5), 475-491.

Cooke, P., Heidenreich, M., Braczyck, H.J., 2004. Regional innovation systems. In: The Role of Governance in a Globalized World. Routledge, London.

Cortinovis, N., Xiao, J., Boschma, R., van Oort, F.G., 2017. Quality of government and social capital as drivers of regional diversification in Europe. J. Econ. Geogr. lbx001.

Dewald, U., Truffer, B., 2012. The local sources of market formation: explaining regional growth differentials in German photovoltaic markets. Eur. Plan. Stud. 20 (3), 397-420.

Duranton, G., Puga, D., 2001. Nursery cities: urban diversity, process innovation, and the life cycle of products. Am. Econ. Rev. 91 (5), 1454-1477.

Duranton, G.,Puga, D. 2004. Micro-foundations of urban agglomeration economies, handbook of regional and urban economics. In: Henderson, J.V., Thisse, J.F. (Eds.), Handbook of Regional and Urban Economics, Edition 1, vol. 4. Elsevier pp. 2063-2117 (chapter 48).

Florida, R, 2002. The Rise of the Creative Class, Basic Books, New York.

Geels, F.W., 2002. Technological transitions as evolutionary reconfiguration processes: a multi-level perspective and a case-study. Res. Policy 31 (8-9), 1257-1274.

Geels, F.W., Deuten, J., 2006. Local and global dynamics in technological development: a socio-cognitive perspective on knowledge flows and lessons from reinforced concrete. Sci. Public Policy 33 (4).

Geels, F.W., Raven, R., 2006. Non-linearity and expectations in niche-development trajectories: ups and downs in Dutch Biogas development (1973-2003). Technol. Anal. Strateg. Manag. 18 (3-4), 375-392.

Geels, F.W., Schot, J., 2010. The dynamics of transitions: a socio-technical perspective. In: Transitions to Sustainable Development: New Directions in the Study of Long Term Transformative Change. Routledge, pp. 11-104.

Gertler, M.S., Wolfe, D.A., 2004. Ontario's regional innovation system: the evolution of knowledge-based institutional assets. In: Cooke, P., Heidenreich, M. Braczyck, H.J. (Eds.), Regional Innovation Systems. The Role of Governance in a Globalized World. Routledge, London, pp. 91-124.

Grasseni, C., 2014. Seeds of Trust. Italy' s Gruppi di Acquisto Solidale (Solidarity Purchase Groups). J. Political Ecol. 21 (March), 178-192.

Hansen, T., Coenen, L., 2014. The geography of sustainability transitions: review synthesis and reflections on an emergent research field. Environ. Innov. Soc. Transit. $1-18$

von Hippel, E., 1986. Lead users: a source of novel product concepts. Manag. Sci. 32
(7), 791-805

Hoogma, R., Kemp, R., Schot, J., Truffer, B., 2002. Experimenting for Sustainable Transport: the Approach of Strategic Niche Management. Spon Press, London.

Jaffe, A.B., Trajtenberg, M., Henderson, R., 1993. Geographic localization of knowledge spillovers as evidenced by patent citations. Q. J. Econ. 108 (3), 577-598.

Jolly, S., Raven, R., Romijn, H., 2012. Upscaling of business model experiments in offgrid PV solar energy in India. Sustain. Sci. 7, 199-212.

Kemp, R., Schot, J., Hoogma, R., 1998. Regime shifts to sustainability through processes of niche formation: the approach of strategic niche management. Technol. Anal. Strateg. Manag. 10 (2), 175-198.

Kenney, M., 2003. Understanding Silicon Valley: the Anatomy of an Entrepreneurial Region. Stanford University Press.

Longhurst, N., 2015. Towards an 'alternative' geography of innovation. Environ. Innov. Soc. Transit. 17.

Loorbach, D.A., 2007. Transition Management: New Mode of Governance for Sustainable Development. International Books, Utrecht.

Malerba, F., 2005. Sectoral systems: how and why innovation differs across sectors. In: The Oxford Handbook of Innovation, pp. 380-406.

Maskell, P., Malmberg, A., 1999. Localised learning and industrial competitiveness. Camb. J. Econ. 23 (2), 167-185.

de Moor, T., 2013. Homo cooperans. Institutions for collective action and the compassionate society. Utrecht University, Utrecht.

Moulaert, F., Nussbaumer, J., 2005. The social region. Eur. Urban \& Reg. Stud. 12 (1), 44-64.

Neffke, F., Henning, M., Henning, M., Boschma, R., 2011. How do regions diversify over time? Industry relatedness and the development of new growth paths in regions. Econ. Geogr. 87 (3), 237-265.

Nooteboom, B., 2000. Learning and Innovation in Organizations and Economies. Oxford University Press, Oxford.

OECD \& World Bank, 2014. Making Innovation Policy Work. Learning from Experimentation. OECD publishing.

van Oort, F.G., Bosma, N.S., 2012. Agglomeration economies, inventors and entrepreneurs as engines of European regional economic development. Ann. Reg. Sci. 51 (1), 213-244.

Ponds, R., van Oort, F., Frenken, K., 2010. Innovation, spillovers and universityindustry collaboration: an extended knowledge production function approach. J. Econ. Geogr. 10 (2), 231-255.

Raven, R., Van den Bosch, S., Weterings, R., 2010. Transitions and strategic niche management: towards a competence kit for practitioners. Int. J. Technol. Manag. $51,57-74$.

Rogers, E.M., 2003. Diffusion of Innovations. The Free Press, New York.

Rotmans, J., Kemp, R., Van Asselt, M., 2001. Emerald Article: more evolution than revolution: transition management in public policy. Foresight 3, 15-31.

Rotmans, J., 2005. Societal Innovation: between Dream and Reality Lies Complexity. Erasmus university of Rotterdam. Inaugural adress.

Rotmans, J., Loorbach, D., 2010. Towards a better understanding of transitions and their governance: a systemic and reflexive approach. In: Transitions to Sustainable Development: New Directions in the Study of Long Term Transformative Change. Routledge, pp. 199-220.

Schliwa, G., McCormick, K., 2016. Living labs Users, citizens and transitions. In: Evans, J., Karvonen, A., Raven, R. (Eds.), The Experimental City. Routledge.

Schot, J., Geels, F.W., 2008. Strategic niche management and sustainable innovation journeys: theory, findings, research agenda, and policy. Technol. Anal. Strateg. Manag. 20 (5), 537-554.

Sengers, F. Wieczorek, A.J., Raven, R., 2016. The role of experiments in sustainability transitions: a systematic literature review. Technol. Forecast. Soc. Change, 00401625 (in press).

Seyfang, G., Smith, A., 2007. Grassroots innovations for sustainable development: towards a new research and policy agenda. Environ. Polit. 16 (4), 584-603.

Smith, A., Raven, R., 2012. What is protective space? Reconsidering niches in transitions to sustainability. Res. policy 41, 1025-1036.

Spencer, G.M., 2015. Knowledge neighbourhoods: urban form and evolutionary economic geography. Reg. Stud. 49 (5), 883-898.

Sterling, S., 2007. Riding the storm: towards a connective cultural consciousness. In: Wals, A.E.J. (Ed.), Riding the Storm: towards a Connective Cultural Consciousness. Social learning towards a sustainable world. Wageningen Academic Publishers, pp. 63-82.

Tödtling, F., Trippl, M., 2005. One size fits all? Res. Policy 34 (8), 1203-1219.

Truffer, B., Coenen, L., 2012. Environmental innovation and sustainability transitions in regional studies. Reg. Stud. 46 (1), 1-21. 